\title{
In regard to the letter by Li and Yang on the article "Which immobilization is better for distal radius fracture? A prospective randomized trial"
}

\author{
Carlo Gamba ${ }^{1}$ (D) Felipe Andrés Mingo-Fernandez ${ }^{2} \cdot$ Xavier Lizano-Diez $^{2} \cdot$ Marta Cuenca-Llavall $^{2}$. \\ Fernando Santana-Perez ${ }^{2}$
}

Received: 21 January 2018 / Accepted: 23 January 2018 / Published online: 2 February 2018

(C) SICOT aisbl 2018

Dear Editor,

Recently, some doubts relative to the methodological aspects of the article "Which immobilization is better for distal radius fracture? A prospective randomized trial" have been expressed $[1,2]$. In a letter to the Editor, Li and Yang cast doubt on the way in which immobilization was changed from the aboveelbow to the below-elbow cast at the third week, at which time a radiological follow-up was carried out. Due to the importance and incidence of such fractures (distal radius fractures-DRF), it is very important to explain every aspect of this trial and provide all the necessary information to understand the conclusions drawn at the end of the research better.

As stated by $\mathrm{Li}$, the clinical and radiological follow-ups were made at weeks one, three, and six. Every visit consisted of first carrying out proper radiological explorations and then checking the clinical situation of the patient. The subjects included in the above-elbow group (B group) had their radiological control first. As was done with all the patients and during the clinical visit, their cast was just cut with a saw and converted in a below-elbow type. Therefore, we think that this could not have interfered with loss of reduction because the cast was not removed and fracture was not manipulated.
Moreover, the fact that the most important loss of reduction occurred during first three weeks supports the idea of not needing further elbow immobilization after that time.

We appreciate the thought given to those issues in this article and hope this letter can help to clarify the results reported with the end of having more data when treating DRF.

\section{Compliance with ethical standards}

Conflict of interest The authors declare that they have no conflict of interest.

\section{References}

1. Gamba C, Fernandez FAM, Llavall MC, Diez XL, Perez FS. Which immobilization is better for distal radius fracture? A prospective randomized trial. Int Orthop 2017 Jun 3. doi:https://doi.org/10.1007/ s00264-017-3518-y

2. Li H, Yang L. In regards to the article by Gamba et al.:"Which immobilization is better for distal radius fracture? A prospective randomized trial". Int Orthop $2017 \mathrm{Jul}$ 28. doi:https://doi.org/10. 1007/s00264-017-3575-2
Carlo Gamba

CGamba@parcdesalutmar.cat

Universitat Autonoma Barcelona, Hospital del Mar, Barcelona, Spain

2 Hospital del Mar, Barcelona, Spain 